\title{
Public perception of autonomous vehicles: a brief review
}

\author{
A percepção pública de veículos autônomos: uma breve revisão \\ La percepción pública de los vehículos autónomos: una breve revisión
}

Received: 12/01/2021 | Reviewed: 12/06/2021 | Accept: 12/10/2021| Published: 12/18/2021

\author{
Luísa Muglia Souza \\ ORCID: https://orcid.org/0000-0003-3493-7179 \\ Universidade Federal de Juiz de Fora, Brazil \\ E-mail: luisa.muglia@engenharia.ufjf.br \\ José Alberto Barroso Castañon \\ ORCID: https://orcid.org/0000-0002-9799-6857 \\ Universidade Federal de Juiz de Fora, Brazil \\ E-mail: jose.castanon@engenharia.ufff.br
}

\begin{abstract}
There is huge speculation that autonomous vehicles (AVs) will improve urban traffic conditions by enhancing mobility, reducing emissions, and bringing safety. However, AV public acceptance represents a key factor to this technology's success. This paper aims to present a brief review of public perceptions of AVs and focuses on how factors such as demographics, safety, ethics, liability, and COVID-19 pandemic can impact this mobility device's acceptance. Overall, it was found that young and more educated males are more likely to adopt AVs, whereas concerns about safety, ethics, and liability can impact negatively on people's perception of them.
\end{abstract}

Keywords: Autonomous vehicles; Public perception; Consumer acceptability.

\section{Resumo}

Há uma grande especulação de que os veículos autônomos (VAs) irão melhorar as condições do tráfego urbano, aumentando a mobilidade, reduzindo as emissões e trazendo segurança. No entanto, a aceitação do público representa um fator chave para o sucesso desta tecnologia. Este artigo tem como objetivo apresentar uma breve revisão das percepções do público sobre VAs e foca em como fatores como dados demográficos, segurança, ética, responsabilidade e a pandemia de COVID-19 podem impactar a aceitação desta forma de mobilidade. No geral, descobriu-se que os homens jovens e com maior escolaridade são mais propensos a adotar VAs, enquanto as preocupações com segurança, ética e responsabilidade podem impactar negativamente na percepção das pessoas sobre eles.

Palavras-chave: Veículos autônomos; Percepção pública; Aceitabilidade do consumidor.

\section{Resumen}

Existe una gran especulación de que los vehículos autónomos (VA) mejorarán las condiciones del tráfico urbano, aumentarán la movilidad, reducirán las emisiones y aportarán seguridad. Sin embargo, la aceptación de la audiencia representa un factor clave en el éxito de esta tecnología. Este artículo tiene como objetivo presentar una breve revisión de las percepciones públicas de los VA y se centra en cómo factores como la demografía, la seguridad, la ética, la responsabilidad y la pandemia de COVID-19 pueden afectar la aceptación de esta forma de movilidad. En general, se encontró que los hombres más jóvenes y con más educación tienen más probabilidades de adoptar AV, mientras que las preocupaciones sobre la seguridad, la ética y la responsabilidad pueden afectar negativamente la percepción que las personas tienen de ellos.

Palabras clave: Vehículos autónomos; Percepción pública; Aceptabilidad del consumidor.

\section{Introduction}

Autonomous vehicles (AVs) are among the most expected technological innovations in the automotive industry ever.

They promise to reduce emissions, improve mobility, and, most importantly, to bring safety. Worldwide, approximately 1.35 million people die each year due to road traffic crashes (WHO, 2020); these events are mainly attributed to drivers' inattention (Bucsuházy et al., 2020). In the United States, human factors were tied to 94\% of crashes at the national level (NHTSA, 2015). Thus, technologies able to correct these mistakes could significantly decrease the number of crashes associated with human choices and behavior (NHTSA, 2016). 
The first AV emerged in the early 1980s when German professor Ernst Dickmanns enabled a Mercedes Benz van to drive autonomously on an empty highway with top speeds of $96 \mathrm{~km} / \mathrm{h}$ for over more than $20 \mathrm{~km}$ (Davidson \& Spinoulas, 2015). Since then, many companies (e.g., Google, Tesla, and Uber) have been putting outstanding effort to develop AVs, mainly in the last decade. Therefore, the Institute of Electrical and Electronics Engineers sees this technology as "the most promising form of intelligent transportation" and predicts it will correspond to 75\% of cars on the road by 2040 (IEEE, 2012).

AVs are classified into six categories, in which level 0 indicates no automation and level 5 corresponds to full selfdriving automation (SAE, 2019). Although the term is highly widespread in engineering sciences, there is a misunderstanding in people's concept about it: 2 out of 5 believe any car able to park itself is considered autonomous (Motional, 2020), when it is considered level 1. Besides, as AVs are also often referred to as "self-driving", "automated" or "driverless", we must warn about the impact of using those terms as synonymous due to the significant difference in public perception of their meanings (Kassens-Noor et al., 2021).

Public perception can change AVs' design, development, and use. Several studies have been conducted to identify people's opinions about this new mobility option. The main objective of this review is to explore and investigate the factors that make people less optimistic towards AVs to determine gaps in the literature and provide recommended research for the future.

\section{Methodology}

This study consists of a narrative, qualitative review; according to the classification proposed by Gil (2002). A literature search was conducted in May 2021 using Google Scholar. To search for articles and reports, the following descriptors were used: "autonomous vehicles", "public perception", “acceptance”, and "perception", using the Boolean operators "AND" and "OR".

Original articles and reports, published in English, from 2012 to 2021, were included. Review articles, from 2020 to 2021, were also considered.

\section{Results and Discussion}

This section presents and discusses the main results about demographic factors; accidents and safety; ethics and liability; and the COVID-19 pandemic and its impact.

\subsection{Demographic factors}

AVs' ascension during the last decade has aroused several researchers' interest. Many surveys have been conducted to recognize elements that might prompt or discourage people from using this technology. Demographics — which include age, gender, education level, country, and household income — are among the most studied factors due to their relevance. In this section, we analyze how each demographic factor can influence the public opinion of AVs.

By analyzing age, surveys showed that younger people show more enthusiasm towards AVs. In the United States, only $12.7 \%$ aged 75 or older would be comfortable in a fully autonomous car, compared to $40 \%$ of people aged $25-34$ (Abraham et al., 2017). Plus, older adults are less excited about owning this kind of vehicle: $43 \%$ showed some interest, compared to $52 \%$ of people aged 18-34 (Piao et al., 2016). The older generations also think of AVs as less beneficial (Lee et al., 2017). On the other hand, seniors consider integrating AVs into their routines in case they become unable to drive in the future (Rahman et al., 2019). These results shed light on the unfamiliarity and the lack of information about this new technology, which scares the elderly and makes them reluctant to accept autonomy in the traffic environment. 
From another perspective, gender can also influence perceptions of AVs. Typically, men are more interested in the automotive industry and its innovation, and the situation is not different when it comes to driverless vehicles. In a survey conducted by Abraham et al. (2017), only 14.3\% of women stated that they would feel comfortable with full autonomy, compared to $30 \%$ of men. In addition, Piao et al. (2016) found that $64 \%$ of males would consider using this technology, while only $55 \%$ of females stated the same. Furthermore, individuals' concerns may also change according to gender: men are more worried about liability and less worried about the vehicle's control (Howard \& Dai, 2014). Schoettle \& Sivak (2014a) even found that women believe that benefits related to the use of AVs are unlikely to occur. Results like these show that females are yet to gain confidence in autonomous cars.

Moreover, perceptions can change due to educational levels. According to Schoettle \& Sivak (2014a), higher expectations on AVs are tied to higher academic degrees; bachelors are less concerned than those with lower education levels. This suggests that more educated people perceive the new technology more positively. Additionally, we can associate this factor with surveys participants' household income and where they live. Since most surveys have been conducted in the United States, people with higher education usually live in the suburbs and have a higher income. These factors are also connected to a greater perception of AVs. As verified by Rahman et al. (2019), residents in suburban areas are more likely to be optimistic about the new mobility option than people from rural or urban areas. On the other hand, lower-income people are particularly concerned about safety and giving up control (Howard \& Dai, 2014).

The income factor is also tied to the country where the surveys were conducted; most of them were in the United States, the United Kingdom, Australia, and Asian countries, such as China, Japan, and Pakistan. According to Kyriakidis et al., (2015), people from more developed countries are more worried about cybersecurity and sharing their data, whereas individuals from developing countries do not consider this as a threat, but as a benefit for their safety and for improving the efficiency of road traffic. Yet, we must consider that, although low and middle-income countries have approximately $60 \%$ of the world's vehicles, $93 \%$ of the global road crash fatalities take place there (WHO, 2020), which can justify their concerns on safety. In general, people from China and India have more positive opinions about AVs compared to the ones from the US and UK (Schoettle \& Sivak, 2014b). A greater perception of this technology can be expected in Asian countries, as their governments are focused on promoting initiatives for decreasing emissions caused by the traffic (Daily et al., 2017).

Lastly, drivers' experience is a relevant factor to the perception of AVs. As expected, more experienced drivers do not believe that autonomy will turn motorways into safe (Richardson \& Davies, 2016); they may trust their driving skills more than a computer's (Bansal \& Kockelman, 2018). Otherwise, opinions can change when it comes to passengers and pedestrians. Passengers see AVs as risky as human-operated vehicles, whereas for pedestrians the technology is perceived as less risky (Hulse et al., 2018). Furthermore, although experienced drivers may show some enthusiasm towards AVs, they still think of manual driving as the most enjoyable mode of driving (Kyriakidis et al., 2015). In summary, the automotive industry has yet to find a way to convince experienced drivers about driverless vehicles benefits.

\subsection{Accidents and safety}

To adopt new technologies, safety is one of the factors that people are more concerned about. In a survey conducted by Motional (2020), it was found that $65 \%$ of respondents consider safety a top priority and the main consideration before using an AV. The desire to feel safe comes even before other factors such as laws and costs: whereas $82 \%$ rank safety as the most decisive aspect to adopt the new mobility option, 12\% choose laws, and 6\% state costs come first (Casley et al., 2013). This means that people's perceptions of AVs could be even greater if the automotive industry focused on developing safer vehicles and on uncovering their manufacturing process. So that an AV could be accepted by the public, it should be able to decrease current traffic fatalities in the proportion of 75-80\% (Liu et al., 2019). 
However, understanding the safety behind an AV is a complex task, and we must have basic knowledge of the vehicle's functioning to comprehend that. In general, its operation involves three major sensors: camera, radar, and Light Detection and Ranging (LiDAR) — nowadays, the first two support human-operated vehicles (HOV) in tasks like parking and driving assistance. Cameras are useful for visualization in limited conditions. Radars, on the other hand, can help cameras with their limitations and are also able to detect speeds and distances with precision. Lastly, a LiDAR is what makes a vehicle operate autonomously: it uses pulsing lasers and allows AVs to construct 3D views (Othman, 2021). As sensor data alone cannot operate an AV, a "sensor fusion" occurs and the inputs are fed into an AI computer, which allows the vehicle to make driving decisions (Burke, 2019). Figure 1 below shows how an AV operates.

Figure 1. AVs' operation.

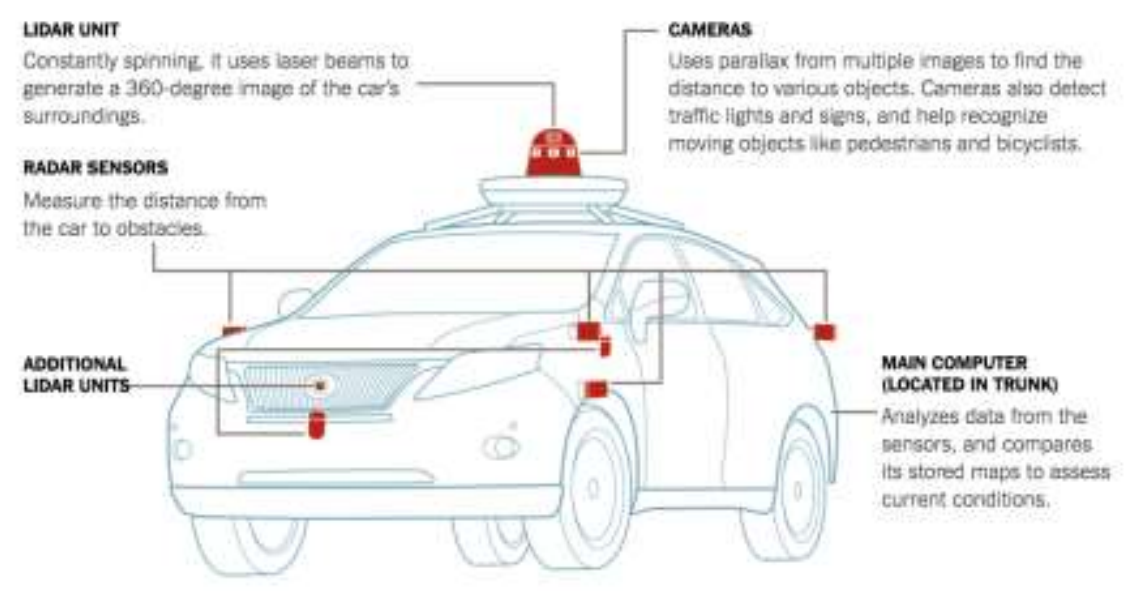

Source: Metz (2018).

As programming a vehicle to interact with the whole environment around it is extremely challenging, machine learning (ML) is used to solve this difficulty. It operates by collecting empirical data from real situations which are treated to train the vehicle to react prudently (VIA, 2019). Nevertheless, with ML, computers learn patterns that are not explicit even to the developers, which implicates that full transparency about an AV operation is impossible (Shariff et al., 2017). Thus, technological maturation is required to increase people's trust in AVs' safety.

Plus, mass media can help increase a negative public perception of AVs' safety. By reporting crashes and fatalities, it promotes on consumers a biased view of the new mobility option (Du et al., 2021). In the last years, several accidents involving vehicles operating autonomously have been reported, the most remarkable ones are shown in table 1. In a similar period, Richardson and Davies (2016) perceived that, unexpectedly, the overall perception of AVs has become more negative, thereby the considerable number of widely reported crashes during this interval can be associated with this increasing negative perception. This leads us to believe that obstacles related to the mass adoption of AVs are psychological instead of technological, as proposed by Shariff et al. (2017). 
Research, Society and Development, v. 10, n. 16, e571101624236, 2021

(CC BY 4.0) | ISSN 2525-3409 | DOI: http://dx.doi.org/10.33448/rsd-v10i16.24236

Table 1. Notable reported accidents involving AVs.

\begin{tabular}{|c|c|c|c|c|c|c|}
\hline Company & Model & Date & Location & Damage & Description & Source \\
\hline Tesla & $\mathrm{S}$ & Jan, 2016 & Hebei, China & Fatal accident & $\begin{array}{l}\text { The car was driving in autopilot mode and crashed into the back of another } \\
\text { vehicle while driving on a highway. Only two years later, Tesla admitted } \\
\text { the autopilot feature failed. }\end{array}$ & $\begin{array}{l}\text { Boudette, 2016; } \\
\text { Goh, 2016; Wei, } 2018\end{array}$ \\
\hline Google & Lexus & Feb, 2016 & California, US & $\begin{array}{l}\text { Minor property } \\
\text { damage, no injuries }\end{array}$ & $\begin{array}{l}\text { The vehicle was driving autonomously at } 2 \mathrm{mph} \text { and crashed with a bus } \\
\text { driving at } 15 \mathrm{mph} \text {. Some damage was provoked to the AV. }\end{array}$ & Gibbs, 2016; Ziegler, 2016 \\
\hline Tesla & $\mathrm{S}$ & May, 2016 & Florida, US & Fatal accident & $\begin{array}{l}\text { The vehicle was in autopilot mode and failed to recognize a white tractor- } \\
\text { trailer crossing the highway. The Tesla driver died, whereas the truck } \\
\text { driver was uninjured. }\end{array}$ & $\begin{array}{l}\text { Lee, 2016; Tesla, 2016; } \\
\text { Yadron \& Tynan, } 2016\end{array}$ \\
\hline Tesla & $\mathrm{X}$ & Mar, 2018 & California, US & Fatal accident & $\begin{array}{l}\text { As the AV approached an exit on a highway, it crashed into a concrete } \\
\text { barrier. The driver died. }\end{array}$ & Levin, 2018; Stewart, 2018 \\
\hline Volvo & XC90 & Mar, 2018 & Arizona, US & Fatal accident & $\begin{array}{l}\text { An autonomous Uber caused the first recorded case of a pedestrian killed } \\
\text { by an AV. The car was driving at } 39 \mathrm{mph} \text { and required a safety driver who } \\
\text { was distracted. It was revealed later that the vehicle could not recognize } \\
\text { jaywalkers. }\end{array}$ & $\begin{array}{l}\text { BBC, 2020; McCausland, } \\
2019 \\
\text { Wakabayashi, } 2018\end{array}$ \\
\hline Google & $\begin{array}{l}\text { Waymo } \\
\text { van }\end{array}$ & May, 2018 & Arizona, US & $\begin{array}{l}\text { Significant property } \\
\text { damage, minor } \\
\text { injuries }\end{array}$ & $\begin{array}{l}\text { A Honda sedan driven by a human swerved to avoid another car and } \\
\text { crashed into the Waymo van. Later, it was found that the AV was in } \\
\text { manual mode. }\end{array}$ & $\begin{array}{l}\text { Hawkins, 2018; Weise, } \\
2018\end{array}$ \\
\hline Tesla & $\mathrm{S}$ & Apr, 2021 & Texas, US & Fatal accident & $\begin{array}{l}\text { Two men died after the vehicle hit a tree and burst into flames. It is not } \\
\text { clear whether the vehicle was being operated by a human. }\end{array}$ & Gross, 2021; Lyons, 2021. \\
\hline
\end{tabular}

Source: Authors. 
Ultimately, we must consider that although bad reactions are expected after fatal AV crashes in the next few years (Shariff et al., 2017), it is assumed that they will reduce fatalities related to multitasking and impaired drivers. This advantage could instigate people to use driverless vehicles. Eventual consumers express a likelihood to perform other activities while driving, mainly observing the scenery and interacting with other passengers (Raphael et al., 2018). Furthermore, people would also feel tempted to use an AV after taking side effects medication or while being over the alcohol limit (Payre et al., 2014). So, even though consumers may feel uncomfortable with safety when AVs become widely used at first, their trust might get higher as the benefits are perceived.

\subsection{Ethics and liability}

Programming an autonomous machine to act ethically is one of today's greatest challenges, and that is not different when it comes to AVs. Although we expect these vehicles will rarely crash, the public needs to be prepared for the inevitability of accidents. We must assume we will have to face situations that are similar to the trolley problem (Thomson, 1976).

When a crash is unavoidable, an AV should act to care for life and minimize harm. According to the IEEE Code of Ethics (IEEE, 2020), people should be treated with respect, regardless of their "race, religion, gender, disability, age, national origin, sexual orientation, gender identity, or gender expression". MIT researchers created a platform called "Moral Machine" where individuals could express their opinions about how an AV should act in an inevitable accident, choosing who should die and who should live. In contrast to what was ethically expected, there was a strong preference for saving some groups of characters, mostly children over elderly, women over men, humans over pets, and higher status over lower status (Awad et al., 2018).

Even so, policymakers cannot rely on experiments like these to regulate AVs. This could happen in case people would share their opinions worldwide; then, machine ethics would be universal. Otherwise, cultural factors can influence public opinion towards AVs ethics, as shown in Table 2 below.

Table 2. Impact of cultural factors on people's moral preferences.

\begin{tabular}{|c|c|}
\hline Cultural factor & Impact \\
\hline Countries with proximity & Closer moral preferences \\
\hline $\begin{array}{l}\text { Eastern, collectivistic countries (e.g., } \\
\text { China and Japan) }\end{array}$ & Preference for sparing the old over the young \\
\hline $\begin{array}{l}\text { Western, individualistic countries } \\
\text { (e.g., UK and US) }\end{array}$ & Strong preference for sparing more lives in all situations \\
\hline Low-income countries & More tolerance to jaywalkers \\
\hline $\begin{array}{l}\text { Countries with a high level of } \\
\text { economic inequality }\end{array}$ & Gaps in treatments between high and low social status \\
\hline Southern countries & Preference for sparing women and fit individuals \\
\hline
\end{tabular}

Source: Awad et al. (2019).

Overall, in handling these situations, people, as individuals, believe AVs should act in a utilitarian way (i.e., sparing more lives, regardless of who they are). However, as consumers, they put extra weight on their own passengers' safety, expressing a desire for self-protective cars (Shariff et al., 2017). This puts manufacturers and regulators in a tough position: they must be consistent, avoid scandals, and yet, they cannot discourage consumers (Bonnefon et al., 2016). On the other hand, if the regulation takes too long, we will still be losing too many lives in the traffic environment. 


\subsection{COVID-19 pandemic and its impact}

During the last decade, people have been introduced to new mobility choices, including the AVs, and they could acquire some knowledge and form an opinion about these options. In a survey conducted by Richardson and Davies (2018), only $2.5 \%$ of respondents manifested no prior awareness of AVs, representing an increase of $50 \%$ from three years back. However, people are still at an early stage in understanding these technologies, so it is expected that their opinions will change quickly over the following years (Bansal \& Kockelman, 2018). This abrupt transition in our transportation system can be facilitated by events that require technological advances in a time of crisis, such as the COVID-19 pandemic.

Because of social distancing, people have been reconsidering their transportation options. In the United States, 1 in every 5 consumers shows more interest in AVs now than they used to before the pandemic (Motional, 2020). During this time, the usage of buses and subways have been discouraged to avoid coronavirus transmission, so that consumers had to think about alternative methods of transportation. Long-term effects may still exist; a notable percentage of the population will be afraid to travel in crowded public transportation even when a vaccine is available for everyone (Wiseman, 2021). The fear of other viruses and the lack of trust in the vaccine can encourage people to change their domestic travel habits. As a result, the COVID-19 outbreak is expected to accelerate acceptance to AVs to supply public transport services.

\section{Conclusion}

Since the 1980s, AVs have passed through great improvements so that they could be widely used. Because of the coronavirus pandemic, this technology may emerge sooner than expected. Nonetheless, public perception of AVs still represents an obstacle to their acceptance. In general, people are concerned, and eventual fatal crashes that can happen in the overcoming years may cause overreaction and increase fear.

Safety concerns are high; thus, AVs stakeholders should shed light on this. Otherwise, infallibility cannot be promised. Although accidents are unlikely to occur, machines can fail and, due to machine learning, their failures are opaque even to their programmers. This leads us to a critical discussion about ethical dilemmas behind AVs. Along with ethics, questions involving liability in case a crash occurs also impact negatively AVs' public perception.

Several surveys have identified factors that contribute to public perceptions of AVs. Generally, younger and more educated males are more optimistic about this new mobility option in comparison to other groups. However, only a few surveys have been conducted in low-income regions (e.g., in Africa and Latin America), even though they represent a notable portion of global traffic. Future research should focus on those regions. Besides, once AVs are properly operating worldwide, we expect that people's opinions towards them will change rapidly so that surveys consulting individuals' experiences with this technology option should be applied periodically to generate improvements.

\section{References}

Abraham, H., Lee, C., Mehler, B., \& Reimer, B. (2017). Autonomous Vehicles and Alternatives to Driving: Trust, Preferences, and Effects of Age. Transportation Research Board 96th Annual Meeting, January, 1-16.

Awad, E., Bonnefon, J.-F., Shariff, A., \& Rahwan, I. (2019). The Thorny Challenge of Making Moral Machines: Ethical Dilemmas with Self-Driving Cars. NIM Marketing Intelligence Review, 11(2), 42-47. https://doi.org/10.2478/nimmir-2019-0015

Awad, E., Dsouza, S., Kim, R., Schulz, J., Henrich, J., Shariff, A., \& Rahwan, I. (2018). The moral machine experiment: 40 million decisions and the path to universal machine ethics. Nature, 563(8), 59-64.

Bansal, P., \& Kockelman, K. M. (2018). Are we ready to embrace connected and self-driving vehicles? A case study of Texans. Transportation, 45(2), 641675. https://doi.org/10.1007/s11116-016-9745-Z

BBC (2020). Uber's self-driving operator charged over fatal crash. https://www.bbc.com/news/technology-54175359

Bonnefon, J. F., Shariff, A., \& Rahwan, I. (2016). The social dilemma of autonomous vehicles. Science, 352(6293), $1573-1576$. 
Boudette, N. (2016). Autopilot Cited in Death of Chinese Tesla Driver. https://www.nytimes.com/2016/09/15/business/fatal-tesla-crash-in-china-involvedautopilot-government-tv-says.html

Bucsuházy, K., Matuchová, E., Zůvala, R., Moravcová, P., Kostíková, M., \& Mikulec, R. (2020). Human factors contributing to the road traffic accident occurrence. Transportation Research Procedia, 45, 555-561. https://doi.org/10.1016/j.trpro.2020.03.057

Burke, K. (2019). How Does a Self-Driving Car See? https://blogs.nvidia.com/blog/2019/04/15/how-does-a-self-driving-car-see/

Casley, S. V., Jardim, A., \& Quartulli, A. M. (2013). A Study of Public Acceptance of Autonomous Cars. https://web.wpi.edu/Pubs/E-project/Available/Eproject-043013-155601/unrestricted/A_Study_of_Public_Acceptance_of_Autonomous_Cars.pdf

Davidson, P., \& Spinoulas, A. (2015). Autonomous Vehicles - What Could This Mean for the Future of Transport? AITPM National Conference.

Daily, M., Medasani, S., Behringer, R., \& Trivedi, M. (2017). Self-Driving Cars. IEEE Computer Society, 18-23.

Du, H., Zhu, G., \& Zheng, J. (2021). Why travelers trust and accept self-driving cars: An empirical study. Travel Behaviour and Society, 22(June 2020), 1-9. https://doi.org/10.1016/j.tbs.2020.06.012

Goh, B. (2016). Chinese man blames Tesla autopilot function for son's crash. https://www.reuters.com/article/us-tesla-crash-idUSKCN11K232

Gibbs, S. (2016). Google's self-driving car in broadside collision after other car jumps red light. https://www.theguardian.com/technology/2016/sep/26/google-self-driving-car-in-broadside-collision-after-other-car-jumps-red-light-lexus-suv

Gil, A. C. (2002). Como elaborar projetos de pesquisa. Atlas.

Gross, J. (2021). Texas Police Investigate Fatal Tesla Crash Near Houston. https://www.theverge.com/2021/4/18/22390612/two-people-killed-fiery-teslacrash-no-driver

Hawkins, A. (2018). Waymo self-driving minivan involved in crash in Arizona https://www.theverge.com/2018/5/4/17320936/waymo-self-driving-car-crasharizona

Howard, D., \& Dai, D. (2014). Public Perceptions of Self-driving Cars: The Case of Berkeley, California. 93rd Annual Meeting of the Transportation Research Board, 2014(1), 21.

Hulse, L. M., Xie, H., \& Galea, E. R. (2018). Perceptions of autonomous vehicles: Relationships with road users, risk, gender and age. Safety Science, 102(August 2017), 1-13. https://doi.org/10.1016/j.ssci.2017.10.001

IEEE (2012). Look Ma, No Hands! http://www.ieee.org/about/news/2012/5september_2_2012.html

IEEE (2020). IEEE Code of Ethics. https://www.ieee.org/content/dam/ieee-org/ieee/web/org/about/corporate/ieee-code-of-ethics.pdf

Kassens-Noor, E., Wilson, M., Cai, M., Durst, N., \& Decaminada, T. (2021). Autonomous vs. Self-Driving Vehicles: The Power of Language to Shape Public Perceptions. Journal of Urban Technology, 28(3-4), 5-24. https://doi.org/10.1080/10630732.2020.1847983

Kyriakidis, M., Happee, R., \& De Winter, J. C. F. (2015). Public opinion on automated driving: Results of an international questionnaire among 5000 respondents. Transportation Research Part F: Traffic Psychology and Behaviour, 32, 127-140. https://doi.org/10.1016/j.trf.2015.04.014

Lee, D. (2016). US opens investigation into Tesla after fatal crash. https://www.bbc.com/news/technology-36680043

Lee, C., Ward, C., Raue, M., D’Ambrosio, L., \& Coughlin, J. F. (2017). Age differences in acceptance of self-driving cars: A survey of perceptions and attitudes. International Conference on Human Aspects of IT for the Aged Population, 3-13. https://doi.org/10.1007/978-3-319-58530-7_1

Liu, P., Yang, R., \& Xu, Z. (2019). How Safe Is Safe Enough for Self-Driving Vehicles? Risk Analysis, 39(2), 315-325. https://doi.org/10.1111/risa.13116

Lyons, K. (2021). Two people killed in fiery Tesla crash with no one driving. https://www.theverge.com/2021/4/18/22390612/two-people-killed-fiery-teslacrash-no-driver

Metz, C. (2018). How Driverless Cars See the World Around Them. https://www.nytimes.com/2018/03/19/technology/how-driverless-cars-work.html

McCausland, P. (2019). Self-driving Uber car that hit and killed woman did not recognize that pedestrians jaywalk. https://www.nbcnews.com/tech/technews/self-driving-uber-car-hit-killed-woman-did-not-recognize-n1079281

Motional (2020). Mobility Report. https://motional.com/mobility-report

NHTSA (2015). Critical Reasons for Crashes Investigated in the National Motor Vehicle Crash Causation Survey. https://crashstats.nhtsa.dot.gov/Api/Public/Publication/812115\#: :text=In\%20about\%2011\%20percent\%20

NHTSA (2016). Federal automated vehicles policy: Accelerating the next revolution in roadway safety. https://www.transportation.gov/sites/dot.gov/files/docs/AV\%20policy\%20guidance\%20PDF.pdf

Othman, K. (2021). Public acceptance and perception of autonomous vehicles: a comprehensive review. AI and Ethics, 1(3), 355-387. https://doi.org/10.1007/s43681-021-00041-8

Payre, W., Cestac, J., \& Delhomme, P. (2014). Intention to use a fully automated car: Attitudes and a priori acceptability. Transportation Research Part F: Traffic Psychology and Behaviour, 27(PB), 252-263. https://doi.org/10.1016/j.trf.2014.04.009 
Research, Society and Development, v. 10, n. 16, e571101624236, 2021

(CC BY 4.0) | ISSN 2525-3409 | DOI: http://dx.doi.org/10.33448/rsd-v10i16.24236

Piao, J., McDonald, M., Hounsell, N., Graindorge, M., Graindorge, T., \& Malhene, N. (2016). Public Views towards Implementation of Automated Vehicles in Urban Areas. Transportation Research Procedia, 14(0), 2168-2177. https://doi.org/10.1016/j.trpro.2016.05.232

Rahman, M. M., Deb, S., Strawderman, L., Burch, R., \& Smith, B. (2019). How the older population perceives self-driving vehicles. Transportation Research Part F: Traffic Psychology and Behaviour, 65, 242-257. https://doi.org/10.1016/j.trf.2019.08.002

Raphael, S. L., Foster Page, L. A., Hopcraft, M. S., Dennison, P. J., Widmer, R. P., \& Evans, R. W. (2018). A survey of cariology teaching in Australia and New Zealand. BMC Medical Education, 18(1). https://doi.org/10.1186/s12909-018-1176-4

Richardson, E., \& Davies, P. (2016). The Changing Public's Perception of Self-Driving Cars. https://doi.org/10.13140/RG.2.2.34641.02402

SAE (2018), SAE International Releases Updated Visual Chart for Its 'Levels of Driving Automation' Standard for Self-Driving Vehicles. https://www.sae.org/news/press-room/2018/12/sae-international-releases-updated-visual-chart-for-its-\%E2\%80\%9Clevels-of-drivingautomation\%E2\%80\%9D-standard-for-self-driving-vehicles

Schoettle, B., \& Sivak, M. (2014a). A survey of public opinion about autonomous and self-driving vehicles in the US, UK and Australia. https://deepblue.lib.umich.edu/handle/2027.42/108384

Schoettle, B., \& Sivak, M. (2014b). Public Opinion about Self-Driving Vehicles in China, India, Japan, the U.S., the U.K., and Australia. https://deepblue.lib.umich.edu/handle/2027.42/109433

Shariff, A., Bonnefon, J. F., \& Rahwan, I. (2017). Psychological roadblocks to the adoption of self-driving vehicles. Nature Human Behaviour, 1(10), 694696. https://doi.org/10.1038/s41562-017-0202-6

Stewart, J. (2018). Tesla's Autopilot Was Involved in Another Deadly Car Crash. https://www.wired.com/story/tesla-autopilot-self-driving-crash-california/

Tesla (2016). A tragic loss. https://www.tesla.com/nl_NL/blog/tragic-loss

Thomson, J. J. (1976). Killing, Letting Die, and the Trolley Problem. Monist, 59(2), 204-217. https://doi.org/10.5840/monist197659224

VIA (2019). Why Sensor Fusion is the Key to Self-Driving Cars. https://www.viatech.com/en/2019/10/why-sensor-fusion-is-the-key-to-self-driving-cars/

Wakabayashi, D. (2018) Self-Driving Uber Car Kills Pedestrian in Arizona, Where Robots Roam. https://www.nytimes.com/2018/03/19/technology/uberdriverless-fatality.html

Wiseman, Y. (2021). Intelligent Transportation Systems along with the COVID-19 Pandemic will Significantly Change the Transportation Market. The Open Transportation Journal, 15, 11-15. https://doi.org/10.2174/1874447802115010011

Wei, X. (2018). Tesla Admits Autopilot Feature Led to Fatal China Crash in 2016. https://www.yicaiglobal.com/news/tesla-admits-autopilot-feature-led-tofatal-china-crash-in-2016

Weise, E. (2018). Video shows Google self-driving van accident in Arizona. https://www.usatoday.com/story/tech/2018/05/04/google-self-driving-vaninvolved-crash-arizona-driver-injured/582446002/

WHO (2020) Road traffic injuries. https://www.who.int/news-room/fact-sheets/detail/road-traffic-injuries

Yadron, D. \& Tynan, D. (2016). Tesla driver dies in first fatal crash while using autopilot mode. https://www.theguardian.com/technology/2016/jun/30/teslaautopilot-death-self-driving-car-elon-musk

Ziegler, C. (2016). A Google self-driving car caused a crash for the first time. https://www.theverge.com/2016/2/29/11134344/google-self-driving-car-crashreport 